\title{
Factor Structure and Validity Indicators of the Job Content Questionnaire: Discussing Stress in the Work Contexts
}

\author{
Kionna Oliveira Bernardes Santos ${ }^{1}$, Fernando Martins Carvalho², Tânia Maria de Araújo ${ }^{3}$ \\ ${ }^{1}$ Departamento de Fisioterapia, Universidade Federal da Bahia (UFBA), Salvador, Brazil \\ ${ }^{2}$ Departamento de Medicina Preventiva e Social, Universidade Federal da Bahia, Salvador, Brazil \\ ${ }^{3}$ Departamento de Saúde, Universidade Estadual de Feira de Santana (UEFS), Feira de Santana, Brazil \\ Email: kionna.bernardes@gmail.com,fmc.ufba@gmail.com, araujo.tania@terra.com.br
}

How to cite this paper: Santos, K. O. B. Carvalho, F. M., \& de Araújo, T. M. (2016). Factor Structure and Validity Indicators of the Job Content Questionnaire: Discussing Stress in the Work Contexts. Psychology, 7, 1424-1437.

http://dx.doi.org/10.4236/psych.2016.712142

Received: June 19, 2016

Accepted: November 4, 2016

Published: November 7, 2016

Copyright (c) 2016 by authors and Scientific Research Publishing Inc. This work is licensed under the Creative Commons Attribution International

License (CC BY 4.0).

http://creativecommons.org/licenses/by/4.0/

\begin{abstract}
Study assessed the dimensional structure of the Job Content Questionnaire's (JCQ 2.0) main scales in two different work contexts. We evaluated two surveys among Brazilian workers, comprising 3084 health workers and 489 industrial workers. An exploratory factor analysis with oblique Geomin rotation explored the model, and subsequently, a confirmatory factor analysis assessed the factor structure and possible modifications of the model. The internal consistency of JC scales was assessed by using estimates of composite reliability and Cronbach's alpha. The structural model was confirmed, with a good fit in the two studies, despite low factors' loads for some items of "decision authority" and "psychological job demands". We concluded that the JCQ dimensional structure corresponded to its theoretical framework in the two work contexts analyzed.
\end{abstract}

\section{Keywords}

Reproducibility of Results, Stress, Work, Validation Studies, Factor Analysis

\section{Introduction}

The Job Content Questionnaire (JCQ) is a multiscale instrument for evaluating work psychological aspects. The questionnaire evaluates two main dimensions that provide theoretical framework to the Job Strain Model (JSM): psychological demands and job control. The JSM assumes that environmental factors are the main determinants of the occupational stress production process, but it also takes into account individual factors, 
like coping strategies (Karasek, 1979). The JCQ has been used in many cultural and occupational contexts (Kawakami et al., 1995; Niedhammer, 2002; Sale \& Kerr, 2002; Cheng, Luh, \& Guo, 2003; Gimeno, Benavides, Amick, Benach, \& Martinez, 2004; Li, Yang, Liu, Xu, \& Choi., 2004; Edimansyah, Rusli, Naing, \& Mazalisah, 2006; Niedhammer, Ganem, Gendrey, David, \& Degioanni, 2006; Eum et al., 2006; Araújo \& Karasek, 2008; Choi et al., 2008; Phakthongsuk \& Apakupakul, 2008; Choobineh, Ghaem, \& Ahmedinejad, 2011; Gomez-Ortiz \& Moreno, 2009; Griep, Rotenberg, Landsbergis, \& Vasconcellos-Silva, 2011; Mase et al., 2012; Nehzat, Huda, \& Tajuddin, 2014).

JCQ recommended version has 49 items, including latitude of decision, which is the worker's control over their own work, made by decision of authority and discretion ability subscales, psychological requirements, supervisor and social support coworker subscales, physical demands of the job, and job insecurity (Karasek, 1985). A new version of the questionnaire (JCQ 2.0), introducing the emotional demands scale, is under test. Detailed information about JCQ recommended version and its new version is available at http://www.jcqcenter.org.

The multidimensional characteristic of the work psychosocial aspects reveals the complexity of JCQ analysis object (Bakker, Van Veldhoven, \& Xanthopoulou, 2010). JCQ Center researchers constantly review the existing scales and have implemented new scales and subscales, aiming to improve the questionnaire measurement capacity.

Several studies have analyzed the JCQ dimensional structure. However, different evaluation methods and the instrument different versions have hampered the comparability of results drawn from these studies. The JCQ dimensional structure was mainly described by means of exploratory techniques (Kawakami et al., 1995; Cheng et al., 2003; Gimeno et al., 2004; Li et al., 2004; Edimansyah et al., 2006; Eum et al., 2006; Araújo \& Karasek, 2008; Choobineh et al., 2011; Gomez-Ortiz \& Moreno, 2009; Mase et al., 2012; Nehzat et al., 2014). The confirmatory factorial analysis can improve the construct measurement theory of a research instrument and deepen the analysis when it considers the theoretical framework that presupposes the measure that the instrument will make. According to this technique, the measurement theory previously tested by an exploratory method is used for specifying the number of factors and items that will compose the factorial model (Hair, Black, Babin, Anderson, \& Tatham, 2006). Some studies have already applied this technique to JCQ and have proposed structural changes in this instrument (Niedhammer, 2002; Sale \& Kerr, 2002; Santavirta, 2003; Niedhammer et al., 2006; Choi et al., 2008; Phakthongsuk \& Apakupakul, 2008; Hökerberg et al., 2010; Griep et al., 2011; Hökerberg et al., 2014). This study aimed to assess the dimensional structure of the Job Content Questionnaire's (JCQ) main scales in two different work contexts in Brazil.

\section{Methods}

This study comprised 3573 workers, from two studies conducted in two different occupational contexts. Study 1 evaluated a random sample of 3084 workers in basic 
health care and medium complexity from five cities from State of Bahia, Brazil. The sample was stratified according to geographical área, complexity level and professional groups. Data collection occurred in 2011/2012. Study 2 was a census among 489 permanent workers in a petroleum industry in the Sate of Bahia, Brazil, in 2008 (Fonseca, Araújo, Santos, \& Amado 2014).

\subsection{Research Instrument}

Both studies have used the newest version of the Job Content Questionnaire (JCQ 2.0) to evaluate psychosocial job aspects, measured in Likert-type scales that vary from 1 (strongly disagree) to 4 (strongly agree). Each study evaluated different scales, representing different dimensions of the JCQ. Study 1 evaluated the scales: psychological job demands; Decision latitude (worker control upon the own job, including the decision latitude and skill discretion subscales; social support from supervisor and social support from coworkers; physical job demands; job insecurity, and the emotional demands scale. Study 2 evaluated the same scales, except the emotional demands scale.

\subsection{Data Analysis}

Descriptive analysis. Initially, the workers sociodemographic characteristics (sex, age, and schooling) were described. Subsequently, skewness and kurtosis distributions of the items included in the factorial model were measured. Items presenting absolute values of skewness $>3$ or kurtosis $>7$ were considered as having poor sensitivity (Kline, 1994).

Exploratory and confirmatory factor analysis. Factors were extracted by using parallel analysis, a reliable method that allows the comparison of the empirical sample eigenvalues with those from a random sample generated by the data processing program (Horn, 1965). The scree plot (Cattell, 1966) technique was used for confirming the number of factors extracted by factor analysis.

Preliminarly, an exploratory factor analysis of the JCQ dimensional structure was performed, by using geomin oblique type rotation. Factor loadings $\geq 0.30$ were assumed as relevant for model structure interpretation [24]. Subsequently, a confirmatory factor analysis (CFA) proceeded, in order to evaluate the factor structure acceptability and possible model modifications, by using the software Mplus 7.1 (Muthén \& Muthén, 2012). CFA used the Weighted Least Squares Mean and Variance Adjusted (WLSMV) estimator. Likert scales structure were analysed by using polychoric correlation matrices.

Three indices evaluated the model goodness of fit. The Root Mean Square Error of Approximation (RMSEA) was considered as a tool for sample size adjustment. Values below 0.06 denote that the model fit is good ( $\mathrm{Hu} \&$ Bentler, 1999). Other authors (Brown \& Cudeck, 1993) report that RMSEA values below 0.05 indicate excellent fit; values equal to or below 0.08 indicate a good adjustment; and values equal to or above 0.10 indicate poor adjustment and, therefore, rejection of the model. The Comparative Fit Index (CFI) and the Tucker-Lewis Index (TLI) were also evaluated as incremental fit indices. They compare a chi-square value for a hypothetic model with independent va- 
riables. Both indices vary from 0 to 1 and values above 0.90 indicate adequate fit (Brown, 2006).

\subsection{Internal Consistency}

JCQ internal consistency was evaluated by comparing Composite Reliability (CR) and Cronbach's alpha estimates for the questionnaire scales. Composite Reliability was estimated for each factor according to the items factor loadings and respective measurement errors. CR was obtained by dividing the sum of square of factor loadings $\left(\lambda_{i}\right)$ in each construct by the sum of the error variance terms for the same construct $(\delta \mathrm{i})$. Values $\geq 0.70$ denoted satisfactory internal consistency (Hair et al., 2006).

Cronbach's alpha was calculated by using the Statistical Package for the Social Sciences version 15.0. Values ranging 0.65 - 0.90 indicate satisfactory performance (Nunnaly, 1978).

Criteria for Convergent and Discriminant validity. The indices of composite reliability and average variance extracted (AVE) were taken as criteria to judge the model convergent validity. AVE was evaluated by the average square factor loading. AVE values $\geq 50$ represent adequacy and indicate that at least $50 \%$ of the measurement is due to the extracted construct (Hair et al., 2006). The discriminant validity assessed the multidimensional nature of the instrument by means of the square root of AVE ( $\sqrt{A V E})$, by comparing factors correlations. Discriminant capacity was identified when $\sqrt{A V E}$ value were higher than the correlations values of determined factor with any other factor present in the factorial model (Fornell \& Larcker, 1981).

\subsection{Ethical Aspects}

Studies 1 and 2 have been previously approved by Ethical Boards; the Collective Health Institute of Federal University of Bahia Ethical Board (Process number CAAE 18723813.9.0000.5030) has approved this study.

\section{Results}

Among the health workers (study 1), females (69.1\%) and the medium schooling level (53.0\%) prevailed; among the petroleum industry workers (study 2), males (68.2\%) and higher schooling level prevailed (Table 1). Table 2 presents descriptive statistics for JCQ items distributions. Mean scores varied from 2.26 ("Allows own decisions") to 3.21 ("Treats me with respect") in study 1; and from 2.29 ("Learn new things") to 3.43 (Repetitive Work"), in study 2. In both studies, some items distributions presented low to moderate skewness and kurtosis. In study 1, the items "Lot to say about my job", "No excessive work", "Allows own decisions", and "Requires creative" showed high values of kurtosis. In study 2, the items "People are friendly" and "People support me to do my job" showed the highest values for the same statistics. None of the items presented absolute values of skewness higher than 7 or kurtosis higher than 3 , what could hamper JCQ sensitivity. The parallel analysis and the scree plot technique showed similar results: restriction to six factors in study 1 , and to five factors in study 2 . 
Table 1. Sociodemographic characteristics of two workers populations evaluated by the Job Content Questionnaire, State of Bahia, Brazil, 2008/2012.

\begin{tabular}{ccccc}
\hline & \multicolumn{2}{c}{ Health workers } & \multicolumn{2}{c}{ Petroleum workers } \\
\cline { 2 - 5 } Characteristic & \multicolumn{2}{c}{$(\mathrm{N}=3084)$} & \multicolumn{2}{c}{$(\mathrm{N}=489)$} \\
\cline { 2 - 5 } & $\mathrm{n}$ & $\%$ & $\mathrm{n}$ & $\%$ \\
Sex & & & & \\
Male & 672 & 19.3 & 332 & 68.2 \\
Female & 2405 & 69.1 & 155 & 31.8 \\
Age (years) & & & & \\
$<30$ & 705 & 23.0 & 24 & 4.9 \\
31 to 45 & 1454 & 47.5 & 249 & 50.9 \\
46 to 55 & 587 & 19.2 & 186 & 38.0 \\
56 or more & 315 & 10.3 & 30 & 6.1 \\
Schooling level & & & & \\
Fundamental (1 to 9 years) & 122 & 4.0 & 6 & 1.2 \\
Medium (10 to 12 years) & 1611 & 53.0 & 205 & 42.2 \\
Higher (undergraduate/graduate) & 1309 & 43.0 & 275 & 56.6 \\
\hline
\end{tabular}

Table 2. Descriptive statistics of the job content questionnaire items in two workers populations, State of Bahia, Brazil, $2008 / 2012$.

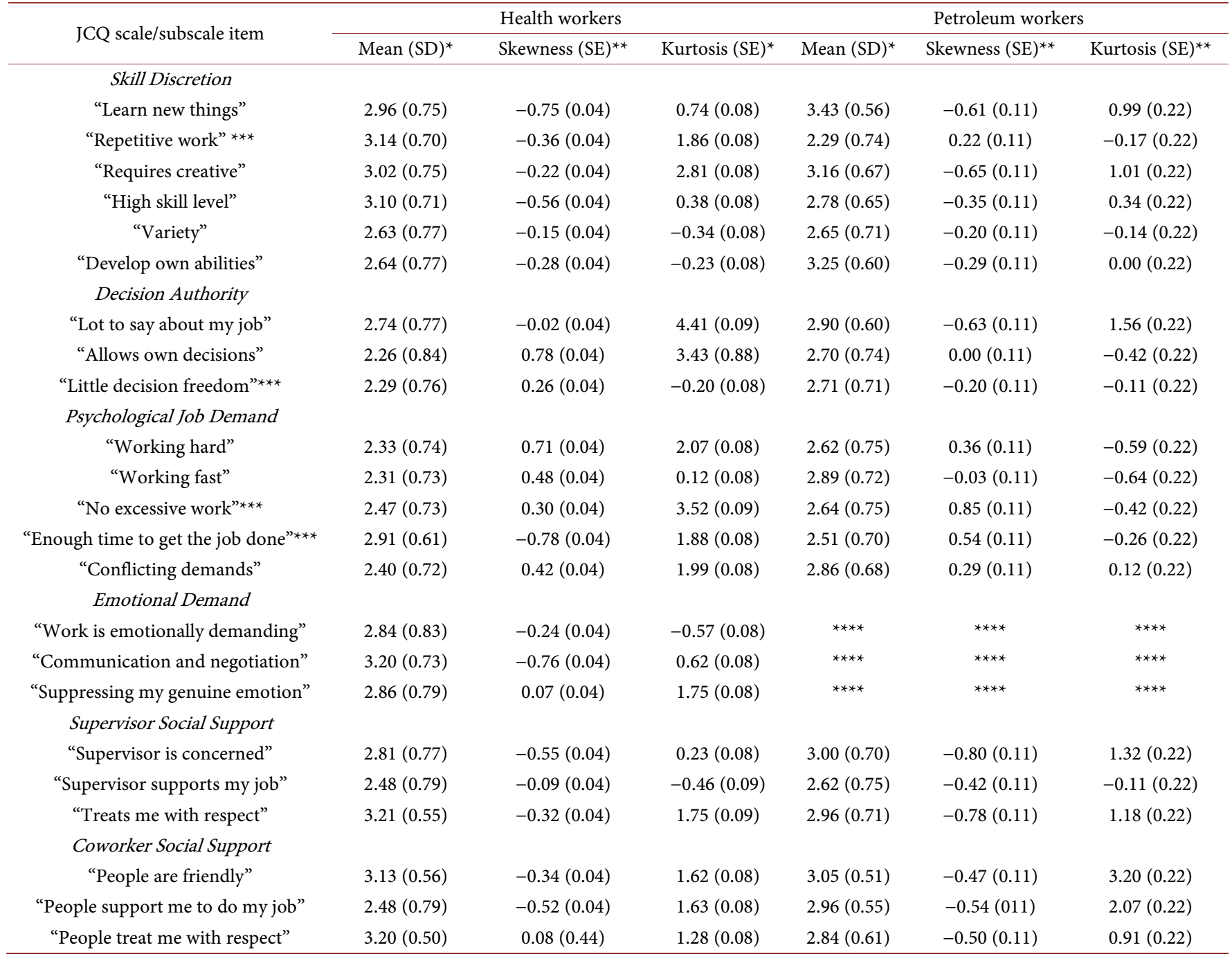


The item "Repetitive work" presented factor loadings $<0.30$, hampering the structural model goodness of fit in study 1 (RMSEA 0.071; CFI 0.90; and TLI 0.88) and in study 2 (RMSEA 0.072; CFI 0.93; and TLI 0.92). Then, the model performance was tested without the item "Repetitive work", and the indices showed good fit in both studies: RMSEA 0.066; CFI 0.91; and TLI 0.90 in study 1; and RMSEA 0.065; CFI 0.95; and TLI 0.94 in study 2 (Table 3 ).

Table 3. Model standardised loading, measurement errors $((\delta))$ and fit indices at confirmatory factor analysis in two workers populations, State of Bahia, Brazil, 2008/2012.

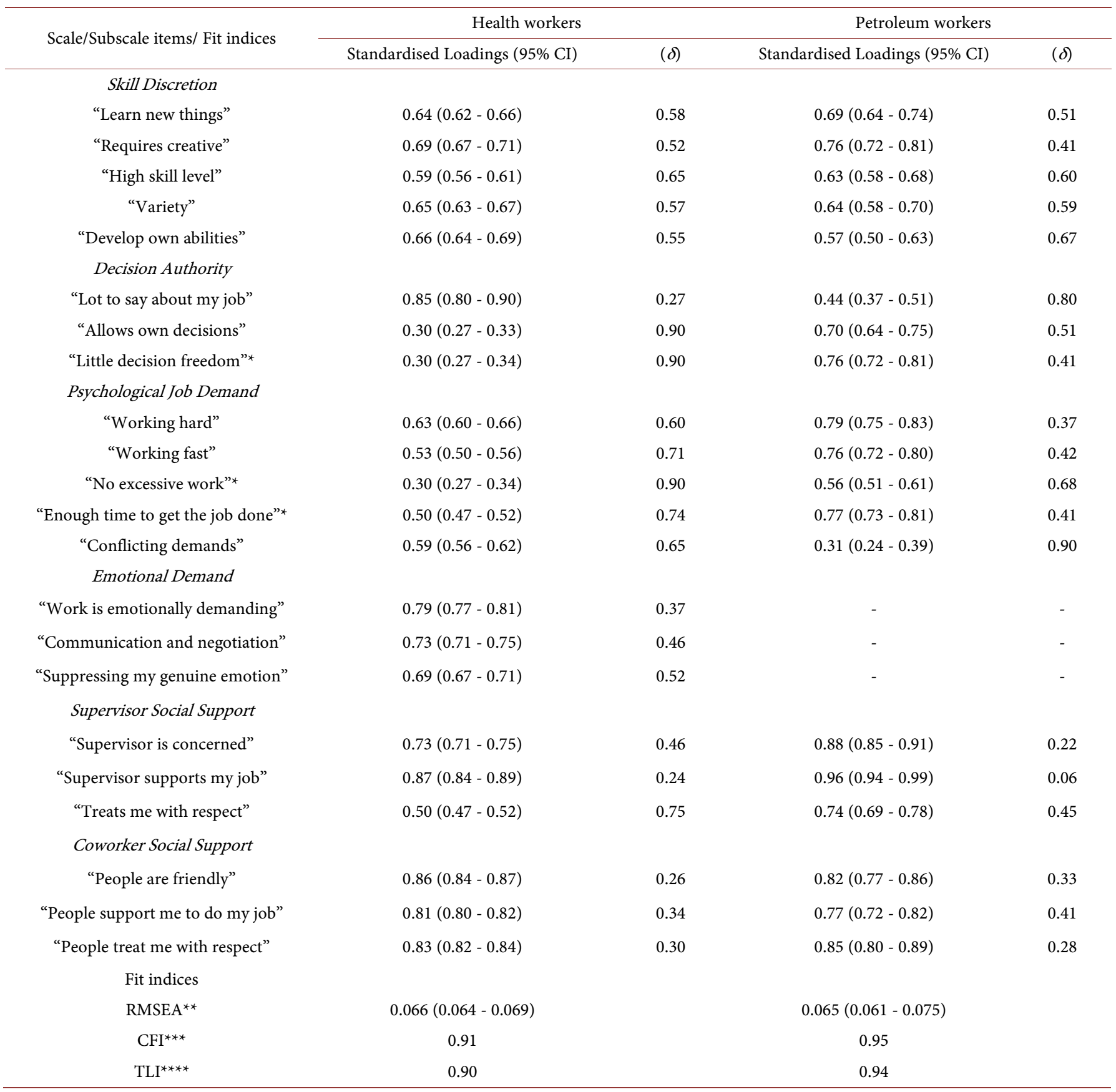


Factor 1, "Skill Discretion", presented similar structure in both studies. Its lowest loading factor value was 0.59 for the item "High skill level", in study 1; and 0.57 for the item "Develop own habilities", in study 2. The item "Requires creative" presented the highest loading values: 0.69 and 0.76 , in study 1 and study 2, respectively. "Authority Decision", a subscale of the Decision Latitude scale, was evaluated in Factor 2. In study 1 , the item "Lot to say about my job" showed the highest loading $(0.85)$ and the other two items showed low loading values $(0.30)$. In study 2 , the same item presented the smallest loading values $(0.44)$, while the other two items presented loading values adequate for factor evaluation $(\geq 0.70)$. Psychological Job Demands were evaluated in Factor 3. The item "Working hard" presented the highest loading value in both studies. The items "No excessive work" from study 1 and the item "Conflicting demands" from study 2 had big measurement errors (0.90), but they were kept in the model for the sake of its dimensional structure evaluation.

The "Emotional Demand" scale was assessed in study 1, only. Factorial loadings varied from 0.69 to 0.79 , in the items "Suppressing my genuine emotions" and "Work is emotionally demanding", respectively.

The scales "Supervisor Social Support" and "Coworker Social Support" showed outstanding high loading factor items. In study 1, all items of the subscale "Coworker Social Support" had loading values greater than 0.80 . However, in the subscale "Supervisor Social Support", the item "Treats me with respect" had loading value of 0.50, only. In study 2 , the item "Treats me with respect" presented loading value of 0.74 , and the remaining ones, values above 0.80 .

In general, the JCQ dimensions showed good internal consistency in both studies, as revealed by adequate Cronbach's alpha coefficients (Table 4). However, Cronbach's alpha coefficients below 0.65 were found for the subscale "Authority Decision" in both studies, and for the scale "Psychological Job Demand", in study 1 . The Composite Reliability presented good correlation (above 0.70 ) in most scales and subscales of both studies, particularly in the scales "Emotional Demand" (0.87), "Coworker Social Support" (0.78), and "Skill Discretion"(0.78) in study 1; and "Supervisor Social Support"(0.90) and "Coworker Social Support" (0.85) in study 2.

Table 4. Cronbach's alpha (C $\alpha$ ), Composite Reliability (CR), Average Variance Extracted (AVE) Square Root of the Average Variance Extracted ( $\mathrm{AVE}$ ) of JCQ in two workers populations, State of Bahia, Brazil, 2008/2012.

\begin{tabular}{cccccccccc}
\hline \multirow{2}{*}{ Scales/Subscale } & \multicolumn{3}{c}{ Health workers } & \multicolumn{4}{c}{ Petroleum workers } \\
\cline { 2 - 9 } & Ca & CR & AVE & $\sqrt{ }$ AVE & Ca & CR & AVE & VAVE \\
\hline Skill Discretion & 0.65 & 0.78 & 0.64 & 0.80 & 0.72 & 0.79 & 0.66 & 0.81 \\
Decision Authority & 0.42 & 0.50 & 0.55 & 0.74 & 0.60 & 0.68 & 0.54 & 0.73 \\
Psychological Job Demand & 0.58 & 0.64 & 0.52 & 0.72 & 0.71 & 0.77 & 0.66 & 0.81 \\
Emotional Demand & 0.80 & 0.87 & 0.83 & 0.91 & - & - & - & - \\
Supervisor Social Support & 0.72 & 0.78 & 0.74 & 0.86 & 0.84 & 0.90 & 0.86 & 0.92 \\
Coworker Social Support & 0.66 & 0.76 & 0.71 & 0.84 & 0.74 & 0.85 & 0.81 & 0.90 \\
\hline
\end{tabular}


AVE values denoted good convergent validity for JCQ scales in the two studies. All scales and subscales showed AVE values above 0.50, representing that at least half of the variance was due to the extracted construct. Social support scales presented the highest proportion of explained variance, in both studies.

Correlations between factors were independently analysed, in each study (Table 5). Among health workers, factors F5 and F6 presented the highest positive correlation (0.58), followed by F1 and F2 (0.52). Relevant negative correlations were observed between factors F3 and F2, F4 and F2, F5 and F3, and F6 and F3. JCQ scales and subcales had adequate discriminant validity, according to the square root of AVE parameter. Among petroleum workers, factors F1 and F2 presented the highest correlation (0.91), followed by F5 and F2 (0.66), and F6 and F5 (0.55). The Decision Latitude subscales "Sill Discretion" and "Authority Decision" had some restrictions concerning their discriminant validity, because they presented at least one factor with correlation value higher than the $\sqrt{ }$ AVE value.

\section{Discussion}

The confirmatory factor analysis revealed correspondence between the theoretical conception and the dimensional structure of the model in the two work contexts. The literature reports that, independently of the JCQ version, the scale "Job Psychological Demand", and the subscales "Skill Discretion" and "Decision Authority" that constitute

Table 5. Correlations between factors $(\varphi)$ of JCQ in two workers populations, State of Bahia, Brazil, 2008/2012.

\begin{tabular}{ccccc}
\hline \multirow{2}{*}{ Factors $^{\star}$ Correlated } & \multicolumn{2}{c}{ Health workers } & \multicolumn{2}{c}{ Petroleum workers } \\
\cline { 2 - 5 } F2 - F1 & $\Phi$ & $95 \mathrm{IC} \%$ & 0.91 & $0.86-0.96$ \\
F3 - F1 & 0.52 & $0.49-0.56$ & 0.22 & $0.14-0.30$ \\
F3 - F2 & 0.13 & $0.09-0.17$ & -0.05 & $0.15-0.03$ \\
F4 - F1 & -0.12 & $0.16-0.08$ & - & - \\
F4 - F2 & 0.40 & $0.37-0.43$ & - & - \\
F4 - F3 & -0.08 & $0.12-0.04$ & - & - \\
F5 - F1 & 0.43 & $0.39-0.46$ & 0.46 & $0.40-0.53$ \\
F5 - F2 & 0.39 & $0.35-0.42$ & 0.66 & $0.60-0.72$ \\
F5 - F3 & 0.45 & $0.41-0.49$ & -0.01 & $0.10-0.07$ \\
F5 - F4 & -0.33 & $0.37-0.29$ & - & - \\
F6 - F1 & 0.09 & $0.05-0.13$ & 0.30 & $0.21-0.39$ \\
F6 - F2 & 0.30 & $0.26-0.33$ & 0.49 & $0.41-0.56$ \\
F6 - F3 & 0.43 & $0.39-0.47$ & -0.03 & $0.13-0.05$ \\
F6 - F4 & -0.20 & $0.23-0.16$ & - & - \\
F6 - F5 & 0.06 & $0.02-0.09$ & 0.55 & $0.48-0.61$ \\
\hline
\end{tabular}

${ }^{\star}$ F1-Skill Discretion; F2-Decision Authority; F3-Psychological Job Demand; F4-Emotional Demand; F5-Supervisor Social Support; F6-Coworker Social Support. 
the "Decision Latitude", are distinct (Griep et al., 2011; Hökerberg et al., 2010; Choi et al., 2008). In spite of the presence of low factorial loadings in some items of "Decision Authority" and "Job Psychological Demand", the structural model was confirmed, with good fit, in both studies. Most scales and subscales presented adequate internal consistency, according to Cronbach's alpha and composite reliability, in both studies. Cronbach's alpha has been frequently used for evaluating the internal consistency of JCQ scales and subscales (Kawakami et al., 1995; Niedhammer, 2002; Sale \& Kerr, 2002; Cheng et al., 2003; Gimeno et al., 2004; Li et al., 2004; Edimansyah et al., 2006; Niedhammer et al., 2006; Eum et al., 2006; Araújo \& Karasek, 2008; Choi et al., 2008; Phakthongsuk \& Apakupakul, 2008; Choobineh et al., 2011; Griep et al., 2011; Mase et al., 2012; Tabatabaee Jabali et al., 2013; Nehzat et al., 2014). However, the isolate use of Cronbach's alpha has been criticised because it yield underestimate measurements, because of the instrument multidimensional nature, and because it violates the model tau-equivalence (Tavakol \& Dennick, 2011; Green \& Thompson, 2005), a condition that assumes that each item measures the same latent trace of the instrument.

The control ("Decision Latitude") dimension, evaluated by the subscales "Skill Discretion" and "Decision Authority", performed distinctly in the two studies, considering the loading factors magnitude of their items. However, the subscales showed positive correlations between them. Other studies have reported moderate correlations (Niedhammer, 2002; Li et al., 2004). "Decision Authority" showed negative, though low, correlations with "Psychological Job Demand" (studies 1 and 2) and with "Emotional Demand" (study 1). The abitity to decide how to do the own job may acts positively upon the tensions produced by the job strain, helping the workers to find ways and strategies adapted to their capacities in order to give adequate answers to the job demands. The moderating effect of the control dimension upon the negative effects of job demands operates this way (Collins, 2008; Bakker et al., 2010). Therefore, the findings of negative correlations between these two work dimensions corroborate such hypothesis.

The "Psychological Job Demand" was positively associated to the "Skill Discretion" in both studies. A plausible explanation considers that work contexts with intellectual and polyvalent demands require continuous updating from the workers in order to cope with the activity specific skills (Kawakami et al., 1995). Another explanation reinforces a positive understanding of the job demands, particularly when associated with the use of resources (workers' abilities and/or organizational context) to obtain career opportunities [20]. From this perspective, demands comprise not only the compliance with the job requirements, but they also learning and achievement of new skills, thereby forging a straight relationship between the work psychological dimensions.

"Repetitive work" presented low factor loading and, for this reason, it was removed from the model. This item has shown irregular performance compared with the other items from the "Skill Discretion" subscale (Niedhammer, 2002; Li et al., 2004; Eum et al., 2006; Hökerberg et al., 2010; Chungkham et al., 2013; Hökerberg et al., 2014). In several contexts, repetitive work is more directly associated to the perception of job 
demands than to a component from the autonomy dimension. When the work occurs under tight managerial control, frequently also occurs the definition of rhythms, intense movements and time pressure, implying in repetitiveness and acceleration of activities. All this process makes repetitive work be perceived as a job demand component. Therefore, the perception of this item can arise dubiety when assessing the worker control upon his job (skill discretion).

The "Psychological Job Demand" scale presented an acceptable structure. The item "No excessive work" had low factor loadings among health workers. Among petroleum workers, the item "Conflicting demands" had low factor loading. This item usually presents low discriminant power and poor correlation with the remaining items, suggesting the need of reviewing this scale structure (Niedhammer, 2002; Sale \& Kerr, 2002; Li et al., 2004; Araújo \& Karasek, 2008). The discussion about the "Psychological Job Demand" scale has focused on the content multidimensionality and on its psychometric deficiencies (Choi et al., 2008). Different work contexts may comprise quantitative (excessive demands) and qualitative (intellectual demands) natures. Therefore, this scale irregular performance can be associated to possible correlations between control ("Decision Latitude") subscales, whereas some work contexts do not have fixed routine but high skill and creativity levels (Mase et al., 2012). In spite of the complexity and the difficulty to evaluate this construct, this study found negative, albeit low, correlations between "psychological job demands" and components of social support and of authority decision. Social support components play important role in the organization and reduction of work burden, and they favour the use of appropriate resources for task execution (Collins, 2008).

This study advanced in the assessment of the emotional demands scale. This scale presented satisfactory internal consistency, according the two indices measured, and items with high factor loadings that discriminated its dimensional structure well. Moderate, positive correlations were observed between this scale and the scale "Psychological Job Demands" and the subscale "Skill Discretion"; and low, positive correlations with the social support subscales. The correlations observed between emotional demands and psychological job demands are coherent, since demanding occupational contexts involve different requirements and dimensions. An increase in a particular dimension implies in increases in the other ones, usually. The correlations between emotional demands and skill discretion suggest the straight relationships between emotional involvement and aspects like learning new knowledge, creativity, and development and use of special skills, components of the skill discretion subscale. Emotional demands, as reported for psychological job demands, may contribute to the development of new skills and behaviors, providing they are kept in a baseline that do not exceed the worker abilities and the resources available to the execution of the job tasks . The correlations between emotional demands and the social support subscales, albeit very low, are apparently contradictory, since negative correlations were expected. However, the detachment of the relationships that prevail within a small group of workers in mutual support to the general job supervision might explain this finding 
(Bakker et al., 2010).

In both studies, social support subscales showed strong correlations, presented high factor loadings that contribute to model interpretation, and their items satisfied the internal consistency criteria. Keeping these subscales in the dimensional structure did not affect the model fit criteria, differing from other studies findings (Hökerberg et al., 2010; Chungkham et al., 2013). As expected, social support subscales showed positive correlations with skill discretion, and decision authority; and negative correlations with psychological job demands, in both studies.

The permanence of the social support dimension and its subscales in the JCQ has been discussed (Sale \& Kerr, 2002; Sanne, Torp, Mykletun, \& Dahl, 2005; Hökerberg et al., 2010; Chungkham et al., 2013; Hökerberg et al., 2014), and most authors approved their preservation in the model (Li et al., 2004; Edimansyah et al., 2006; Eum et al., 2006; Niedhammer et al., 2006; Araújo \& Karasek, 2008; Phakthongsuk \& Apakupakul, 2008; Choobineh et al., 2011; Chungkham et al., 2013; Nehzat et al., 2014). Psychometric evaluations revealed consistent and coherent measurements for the construct evaluated with these subscales, in both studies. The social support subscales performed differently, probably because of the JCQ several formats. The maintenance of the social support dimension this instrument should be determined by theoretical criteria, or by the research subject (Chungkham et al., 2013). Factor loadings, average variance extracted (AVE) and composite reliability indicated convergent validity in the two studies. JCQ scales showed acceptable proportion of extracted variance, even when factor loadings and composite reliability were low. This fact demonstrates that the instrument shares the explained variance, and its items consistently represent the latent construct evaluated by its scales and subscales (Hair et al., 2006).

The JCQ discriminant validity indicator ( $\sqrt{ }$ AVE) had adequate performance in the two studies, revealing the ability of the instrument scales to remain unmodified by constructs that diverge about the proposed measurement object. Nonetheless, in the petroleum workers study, the control subscales did not show good discriminant capacity of the construct, since the high correlations found among factors denote poor distinction among the subscales. Similar results have been reported by other authors (Sanne et al., 2005; Phakthongsuk \& Apakupakul, 2008), who argued that the heterogeneity of the working populations could have affected the discriminant ability of the control subscales.

The work in the health area has strong influence of the worker autonomy and of coworker social support, while the work in the petroleum industry is highly hierarchical and organized in a well-defined institutional space. In spite of these different occupational contexts, the JCQ showed correspondence with its theoretical framework, and has confirmed the structure of its scales and subscales.

The different sizes of the two workers populations investigated is a limitation of this study. Furthermore, the study 2, proposed as a census, had response rate of $65 \%$, only. It was difficult to interpret the contribution to the model of the item "repetitive work", included in the "Skill Discretion" subscale. This result indicates the necessity of moving 
the important item "repetitive work" from the "Skill Discretion" subscale to another scale or subscale of the instrument. The other validity indicators we analysed in this study support the structure proposed by the JCQ for the evaluation of the work subjective characteristics.

\section{Conclusion}

The JCQ dimensional structure corresponded to its theoretical framework in the two work contexts analyzed.

\section{References}

Araújo, T. M., \& Karasek, R. (2008). Validity and Reliability of the Job Content Questionnaire in Formal and Informal Jobs in Brazil. Scandinavian Journal of Work, Environment \& Health, 34, 52-59.

Bakker, A. B., Van Veldhoven, M., \& Xanthopoulou, D. (2010). Beyond the Demand-Control model: Thriving on High Job Demands and Resources. Journal of Personnel Psychology, 9, 3-16. http://dx.doi.org/10.1027/1866-5888/a000006

Brown, M. W., \& Cudeck, R. (1993). Alternative Ways of Assessing Model Fit. In K. A. Bollen, \& J. S. Long (Eds.), Testing Structural Equation Models (pp. 136-162). Newbury Park, CA: Sage.

Brown, T. A. (2006). Confirmatory Factor Analysis for Applied Research. New York: Guilford Press.

Cattell, R. B. (1966). The Scree Test for the Number of Factors. Multivariate Behavioral Research, 1, 245-276. http://dx.doi.org/10.1207/s15327906mbr0102_10

Cheng Y., Luh W. M., \& Guo, Y. L. (2003). Reliability and Validity of the Chinese Version of the Job Content Questionnaire in Taiwanese Workers. International Journal of Behavioral Medicine, 10, 15-30. http://dx.doi.org/10.1207/S15327558IJBM1001_02

Choi, B., Kawakami, N., Chang, S., Koh, S., Bjorner, J., Punnett, L., \& Karasek, R. (2008). A Cross-National Study on the Multidimensional Characteristics of the Five-Item Psychological Demands Scale of the Job Content Questionnaire. International Journal of Behavioral Medicine, 15, 120-132. http://dx.doi.org/10.1080/10705500801929742

Choobineh, A., Ghaem, H., \& Ahmedinejad, P. (2011). Validity and Reliability of the Persian (Farsi) Version of the Job Content Questionnaire: A Study among Hospital Nurses. Easter Mediterranean Health Journal, 17, 335-341.

Chungkham, H. S., Ingre, M., Karasek, R., Westerlund, H., \& Theorell, T. (2013). Factor Structure and Longitudinal Measurement Invariance of the Demand Control Support Model: An Evidence from the Swedish Longitudinal Occupational Survey of Health (SLOSH). PloS ONE, 8, 705-741. http://dx.doi.org/10.1371/journal.pone.0070541

Collins, S. (2008). Statutory Social Workers: Stress, Job Satisfaction, Coping, Social Support and Individual Differences. British Journal of Social Work, 38, 1173-1193.

http://dx.doi.org/10.1093/bjsw/bcm047

Edimansyah, B. A., Rusli, B. N., Naing, L., \& Mazalisah, M. (2006). Reliability and Construct Validity of the Malay Version of the Job Content Questionnaire (JCQ). The Southeast Asian Journal of Tropical Medicine and Public Health, 37, 412-416.

Eum, K. D., Li, J., Juhn, H. J., Parque, J. T., Tak, S. W., Karasek, R., \& Cho, S. I. (2006). Psychometric Properties of the Korean Version of the Job Content Questionnaire: Data from Health Care Workers. International Archives of Occupational and Environmental Health, 80, 497-504. http://dx.doi.org/10.1007/s00420-006-0156-x 
Fonseca, I. S. S., Araújo, T. M., Santos, K. O. B., \& Amado, N. (2014). Social Support and Job Satisfaction in Employees of an Oil Company. Psicología para América Latina, 25, 43-56.

Fornell, C., \& Larcker, D.F. (1981). Evaluating Structural Equation Models with Unobservable Variables and Measurement Error. Journal of Marketing Research, 18, 39-50.

http://dx.doi.org/10.2307/3151312

Gimeno, D., Benavides, G., Amick, B. C., Benach, J., \& Martinez, J. M. (2004). Psychosocial Factors and Work Related Sickness Absence among Permanent and Non-Permanent Employees. Journal of Epidemiology \& Community Health, 58, 870-876. http://dx.doi.org/10.1136/jech.2003.016634

Gomez-Ortiz, V., \& Moreno, L. (2009). Psychosocial Work Factors (Demand-Control and EffortReward Imbalance), Mental Health and Blood Pressure: A Study with School Teachers in Bogotá, Colombia. Universitas Psychologica, 9, 393-407.

Green, S., \& Thompson, M. (2005). Structural Equation Modeling in Clinical Psychology Research. In M. Roberts, \& S. Ilardi (Eds.), Handbook of Research in Clinical Psychology. Oxford: Wiley-Blackwell.

Griep, R. H., Rotenberg, L., Landsbergis, P., \& Vasconcellos-Silva, P. R. (2011). Combined Use of Job Stress Models and Self-Rated Health in Nursing. Revista de Saúde Publica, 45, 145-152. http://dx.doi.org/10.1590/S0034-89102011000100017

Hair, J. F., Black, H. C., Babin, B. J., Anderson, R. E., \& Tatham, R. L. (2006). Multivariate data analysis (6th ed.). Upper Saddle River, NJ: Pearson Prentice Hall.

Hökerberg, Y. H. M., Aguiar, O. B., Reichenheim, M., Valente, J. G., Fonseca, M. J., \& Passos, S. R. (2010). Dimensional Structure of the Demand Control Support Questionnaire: A Brazilian Context. International Archives of Occupational and Environmental Health, 83, 407-416. http://dx.doi.org/10.1007/s00420-009-0488-4

Hökerberg, Y. H. M., Reichenheim, M. E., Faerstein, E., Valente, J. G., Fonseca, M. J., \& Passos, S. R. (2014). Cross-Cultural Validity of the Demand-Control Questionnaire: Swedish and Brazilian Workers. Revista de Saúde Pública, 48, 486-496. http://dx.doi.org/10.1590/S0034-8910.2014048005126

Horn, J. L. (1965). A Rationale and Test for the Number of Factors in Factor Analysis. Psychometrika, 30, 179-185. http://dx.doi.org/10.1007/BF02289447

Hu, L.-T., \& Bentler, P. M. (1999). Cutoff Criteria for Fit Indexes in Covariance Structure Analysis: Conventional Criteria versus New Alternatives. Structural Equation Modeling: A Multidisciplinary Journal, 6, 1-55. http://dx.doi.org/10.1080/10705519909540118

Karasek, R. (1979). Job Demand, Job Decision Latitude, and Mental Strain: Implications for Job Redesign. Administrative Science Quarterly, 24, 285-308. http://dx.doi.org/10.2307/2392498

Karasek RA 1985. Job Content Questionnaire and User's Guide. University of Massachusetts.

Karasek, R. (2008). Low Social Control and Physiological Deregulation-The Stress-Dise- quilibrium Theory, towards a New Demand-Control Model. Scandinavian Journal of Work, Environment \& Health, 34, 117-135.

Kawakami, N., Kobayashi, F., Araki, S., Haratani, T., \& Furui, H. (1995). Assessment of Job Stress Dimensions Based on the Job Demand-Control Model of Employees of Telecommunication and Electric Power Companies in Japan: Reliability and Validity of the Japanese Version of Job Content Questionnaire. International Journal of Behavioral Medicine, 2, 358-375. http://dx.doi.org/10.1207/s15327558ijbm0204_5

Kline, P. (1994). An Easy Guide to Factors Analysis. Abingdon, VA: Routledge, Taylor and Francis Group.

Li, J., Yang, W., Liu, P., Xu, Z., \& Choi, S. I. (2004). Psychometric Evaluation of the Chinese 
(Mainland) Version of Job Content Questionnaire: A Study in University Hospitals. Industrial Health, 42, 260-267.

Mase, J., Ota, A., Inoue, K., Iida, T., Tsutsumi, U., Yatsuya, H., \& Ono, Y. (2012). Reliability and Validity of the Japanese Translated Version of the Swedish Demand-Control-Support Questionnaire. Industrial Health, 50, 467-475.

Muthén, L. K., \& Muthén, B. O. (2012). Mplus User’s Guide (7th ed.). Los Angeles, CA: Muthén \& Muthén.

Nehzat, F., Huda, B. Z., \& Tajuddin, S. H. (2014). Reliability and Validity of Job Content Questionnaire for University Research Laboratory Staff in Malaysia. The Southeast Asian Journal of Tropical Medicine and Public Health, 45, 481-489.

Niedhammer, I. (2002). Psychometric Properties of the French Version of the Karasek Job Content Questionnaire: A Study of the Scales of Decision Latitude, Psychological Demands, Social Support, and Physical Demands in the GAZEL Cohort. International Archives of Occupational and Environmental Health, 75, 129-144. http://dx.doi.org/10.1007/s004200100270

Niedhammer, I., Ganem, V., Gendrey, L., David, S., \& Degioanni, S. (2006). Propriétes psychométriques de la version française des échelles de La demande psychologique, de la latitude décisionnelle et du soutien social du "Job Content Questionnaire" de Karasek: Résultats de I'enquête nationale SUMER. Santé Publique, 18, 413-427. http://dx.doi.org/10.3917/spub.063.0413

Nunnaly, J. (1978). Psychometric Theory. New York: McGraw-Hill.

Phakthongsuk, P., \& Apakupakul, N. (2008). Psychometric Properties of the Thai Version of the 22-Item and 45-Item Karasek Job Content Questionnaire. International Journal Occupational Medicine and Environment Health, 21, 331-344. http://dx.doi.org/10.2478/v10001-008-0036-6

Sale, J. E. M., \& Kerr, M. S. (2002). The Psychometric Properties of Karasek's Demand and Control Scales within a Single Sector: Data from a Large Teaching Hospital. International Archives of Occupational and Environmental Health, 75, 145-152. http://dx.doi.org/10.1007/s004200100289

Sanne, B., Torp, S., Mykletun, A., \& Dahl, A. A. (2005). The Swedish Demand-Control- Support Questionnaire (DCSQ): Factor Structure, Item Analyses, and Internal Consistency in a Large Population. Scandinavian Journal of Public Health, 33, 166-174. http://dx.doi.org/10.1080/14034940410019217

Santavirta, N. (2003). Construct Validity and Reliability of the Finnish Version of the Demand-Control Questionnaire in Two Samples of 1028 Teachers and 630 Nurses. Educational Psychology, 23, 423-436. http://dx.doi.org/10.1080/01443410303208

Tabatabaee Jabali, S. M. T., Ghaffari, M., Pournik, O., Ghalichi, L., Tehrani Yazdi, A. R., \& Motevalian, S. A. (2013). Reliability and Validity of Persian Version of Job Content Questionnaire in Health Care Workers in Iran. International Journal Occupational Medicine and Environment Health, 4, 96-101.

Tavakol, M., \& Dennick, R. (2011). Post-Examination Analysis of Objective Tests. Medical Teacher, 33, 447-458. http://dx.doi.org/10.3109/0142159X.2011.564682 
Submit or recommend next manuscript to SCIRP and we will provide best service for you:

Accepting pre-submission inquiries through Email, Facebook, LinkedIn, Twitter, etc. A wide selection of journals (inclusive of 9 subjects, more than 200 journals)

Providing 24-hour high-quality service

User-friendly online submission system

Fair and swift peer-review system

Efficient typesetting and proofreading procedure

Display of the result of downloads and visits, as well as the number of cited articles

Maximum dissemination of your research work

Submit your manuscript at: http://papersubmission.scirp.org/

Or contact psych@scirp.org 